\title{
Noninvasive Positive Pressure Ventilation in the Management of Post-thyroidectomy Tracheomalacia: Reply
}

\author{
Shun Yu Chi · Fong-Fu Chou
}

Published online: 7 March 2012

(C) Société Internationale de Chirurgie 2012

We deeply appreciate the comments and queries about our article about the treatment of tracheomalacia [1] presented by Sabaretnam and Mishra in their letter to the Editor [2]. Here, we reply to those queries in detail.

Our policy of managing post-thyroidectomy tracheomalacia prior to 2009 was prolonged (at least 7 days) postoperative oropharyngeal intubation prior to bronchoscopy and attempted extubation. In patients with post-extubational dyspnea and stridor in the absence of vocal cord palsy, shown by fiberoptic laryngoscopy, tracheostomy was performed immediately. Although we did resort to tracheostomy in such situations, since we adopted noninvasive positive pressure ventilation (NPPV) as a post-extubation respiratory rescue in January 2009, we have not performed tracheostomy for any patients with tracheomalacia.

Five patients had thyroid malignancy with no loss of tracheal cartilage. Although the tumors proved to be malignant on the final pathology, they presented as longstanding thyroid tumors that had grown very slowly for years, and they did not invade the trachea but compressed it. The weights of the thyroid glands are listed in the table below, which is reproduced from our article. However, we think that the long-term compression on the trachea plays a more important role than the weight of thyroid gland on the formation of tracheomalacia.

The timing of re-extubation and the initiation of NPPV, times that the NPPV was needed, and the entire ICU stay, are shown in the table below. With the exception of patient
2, none of the patients stayed in the ICU longer than 7 days. Compared with our previous practice, by which patients were intubated for at least 7 days, early extubation combined with NPPV shortened the ICU stay by several days.

\begin{tabular}{lclll}
\hline $\begin{array}{l}\text { No. } \\
\begin{array}{l}\text { Weight of } \\
\text { thyroid } \\
\text { gland }(\mathrm{g})\end{array}\end{array}$ & $\begin{array}{l}\text { Timing of } \\
\text { extubation and } \\
\text { initiation of NPPV }\end{array}$ & $\begin{array}{l}\text { Times that need } \\
\text { NPPV support } \\
\text { (days) }\end{array}$ & $\begin{array}{l}\text { Total } \\
\text { ICU stay } \\
\text { (days) }\end{array}$ \\
\hline 1 & 81.1 & 2nd post-op day & 3 & 5 \\
2 & 137.2 & 12th post-op day & 3 & 17 \\
3 & 117.9 & 1st post-op day & 4 & 7 \\
4 & 96.6 & 3rd post-op day & 2 & 5 \\
5 & 75.4 & 2nd post-op day & 3 & 5 \\
6 & 182.4 & 3rd post-op day & 2 & 5 \\
\hline
\end{tabular}

\section{References}

1. Chi S-H, Shih-Chung W, Hsieh K-C et al (2011) Noninvasive positive pressure ventilation in the management of post-thyroidectomy tracheomalacia. World J Surg 35:1977-1983. doi:10.1007/ s00268-011-1178-4

2. Sabaretnam M, Mishra A (2011) Noninvasive positive pressure ventilation in the management of post-thyroidectomy tracheomalacia. World J Surg. doi:10.1007/s00268-011-1369-z 